\title{
ANTICRESE: DIREITO REAL DE GARANTIA OU FORMA ESPECIAL DE PAGAMENTO?
}

\author{
Adriano Stanley Rocha Souza ${ }^{1}$
}

\section{INTRODUÇÃO}

O nosso Código Civil, de maneira absolutamente surpreendente, manteve em seu texto o obsoleto instituto da anticrese (arts. 1.506 a 1.510).

Tal opção legislativa é, no mínimo, curiosa. Em um primeiro momento (Projeto de Código Civil brasileiro de 1965), tal instituto já havia sido dado como retirado de nosso sistema civil ${ }^{2}$. A despeito de sua previsão em nosso ordenamento legal, a anticrese encontrase em completo desuso.

Neste breve estudo, nos propomos a discutir a natureza jurídica que a anticrese sempre recebeu ao longo de sua história, como sendo uma modalidade de garantia real. Discutiremos, também, a sua utilidade nos tempos atuais. Momento em que a diversidade de instrumentos jurídicos postos à disposição do cidadão comum, chega a embaralhar seu raciocínio, levandoo a fazer opção, em seus negócios, sempre pelo instrumento mais conhecido, ou pelo ao menos mais usual, o que colabora para que a anticrese caia cada vez mais no desuso e no desconhecimento.

\section{CONCEITO E NATUREZA JURÍDICA}

A anticrese encontra-se disciplinada em nosso Código Civil nos artigos 1.506 a 1.510, inseridos no Livro III (Direitos Reais), Capítulo IV. Em uma interpretação sistemática, significa dizer que se trata a anticrese de uma modalidade de garantia real em que, "pode o devedor ou outrem por ele, com a entrega do imóvel ao credor, ceder-lhe o direito de perceber em compensação da dívida os frutos e rendimentos (da coisa)" (art. 1.506 do C.C.) - grifos nossos.

Pois bem. Em outras palavras, a anticrese consistiria na entrega, pelo devedor ao credor, de um bem imóvel, para que deste bem, o credor dali retirasse, sob a sua própria administração, o seu crédito junto ao devedor.

\footnotetext{
1 Mestre e Doutor em Direito Processual pela PUC MINAS. Professor de Direito Civil da PUC MINAS. Professor de Direito Civil da Faculdade de Direito de Sete Lagoas. Advogado Militante.

2 Vide PEREIRA, Caio Mário da Silva. Instituições de Direito Civil, vol IV, p. 414, 18. ed. Ed. Forense. Rio de Janeiro, 2004.
} 
Para que possamos questionar a natureza jurídica de garantia real dada à anticrese pelo nosso ordenamento civil, primeiramente teremos que conhecer algumas das características dos chamados Direitos Reais de Garantia.

\subsection{Dos Direitos Reais sobre Coisas Alheias.}

O Código Civil de 1916, ao tratar do Direito das Coisas em seu Livro II da Parte Especial, dedicou um título deste livro (Título III), para cuidar dos chamados DIREITOS REAIS SOBRE COISAS ALHEIAS, em contraposição aos DIREITOS REAIS SOBRE COISAS PRÓPRIAS (Posse e Propriedade), que eram estudados naquele mesmo Livro nos Títulos I e II.

Desta forma, a legislação destacava alguns instrumentos jurídicos que conferiam às pessoas que deles fossem titulares o direito de ter, sobre as coisas de terceiros, direitos tão fortes como os que tinha o proprietário sobre a sua propriedade. Sim. A todos aqueles que fossem titulares de algum daqueles institutos descritos no Livro II do Código Civil de 1916 (Livro III do Código Civil atual) o legislador conferiu a qualificação de titular de um direito real.

E o que significa ser titular de um direito real?

Ser titular de um direito real implica, em última análise, poder gozar de alguns atributos a que não fazem jus aqueles que são titulares de um direito pessoal.

O professor Caio Mário da Silva Pereira ${ }^{3}$ enumera algumas destas vantagens dos Direitos Reais sobre os Direitos Pessoais:

\footnotetext{
“1 - O direito real é oponível erga omnes, enquanto que o direito de crédito o é a um sujeito passivo determinado;

2 - O objeto do direito real é sempre determinado, ao passo que do direito de crédito basta seja: determinável;

3 - $\mathrm{O}$ ius in re exige a existência atual da coisa, em contraposição ao ius ad personam, compatível com a sua futuridade;

4 - O direito real é exclusivo, no sentido de que se não compadece com a pluralidade de sujeitos com iguais direitos;

5 - O direito real adquire-se por usucapião, ao passo que os direitos de crédito não suportam este modo de aquisição;

6 - Os direitos de crédito extinguem-se pela inércia do sujeito, ao passo que os reais conservam-se, não obstante a falta de exercício, até que se constitua uma situação contrária, em proveito de outro titular;

7 - Os direitos reais são providos da prerrogativa de acompanharem a coisa em poder de quem quer que ela se encontre; (seqüela);

8 - O titular do direito real tem a faculdade de receber privilegiadamente em caso de falência ou concurso creditório, sem se sujeitar ao rateio, cabendo-lhe, dentro dos limites de seu crédito, embolsar o produto da venda da coisa gravada (preferência);
}

3 Op. cit. p. 5.

Revista da Faculdade Mineira de Direito, v.12, n. 24, jul./dez. 2009 - ISSN 1808-9429. 
9 - O titular de um direito real, que não possa mais suportar seus encargos, tem a faculdade de abandoná-lo, o que não cabe no tocante aos direitos de crédito;

10 - Os iura in re são suscetíveis de posse, os crédito não são".

A doutrina, por sua vez, dividiu os direitos reais sobre coisas alheias, em duas categorias: os direitos reais sobre coisas alheias de fruição, e os direitos reais sobre coisas alheias de garantia.

O que determina se um dado instituto de direito real sobre coisa alheia pertence a uma ou à outra categoria, é a finalidade para qual aquele instituto fora criado. Ou seja: se a finalidade do instituto é assegurar a terceira pessoa que não seja proprietária do bem o direito de fruir de coisa alheia como se sua fosse, então, o referido instrumento se trata de um direito real de fruição sobre coisa alheia. Ao revés, se o que se procura é ter a coisa alheia simplesmente como garantia de recebimento de um crédito, então, estaremos diante de um instituto de direito real de garantia sobre coisa alheia.

Seja em um grupo ou no outro (fruição ou garantia), o funcionamento dos institutos se dá de forma semelhante: haverá o desdobramento da posse: posse direta e posse indireta. Ou a quem preferir, haverá o desdobramento da propriedade, que deixará de ser plena e passará a ser limitada. Explicamos melhor: a propriedade plena compreende o exercício de cinco atributos: usar, gozar, fruir, dispor e reivindicar. Se algum destes atributos é retirado das mãos do proprietário e passado para mãos de terceiro, a propriedade deixará de ser plena e passará a ser limitada. Graficamente, poderíamos representar tal fato da seguinte forma:

\section{Propriedade plena}

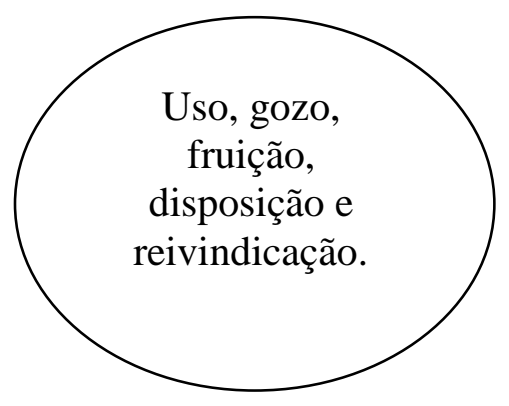

\section{Propriedade limitada}

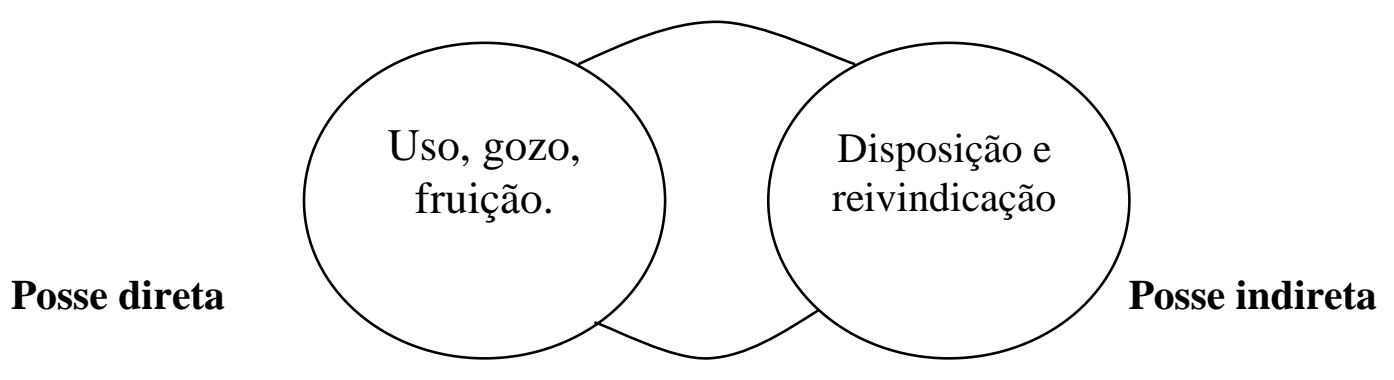


Desta forma, podemos dizer que enquanto um mantém consigo a posse direta sobre a coisa, o outro tem consigo a posse indireta. Ou ainda: enquanto o proprietário mantém consigo o título de proprietário, o terceiro tem o exercício efetivo da posse.

Entretanto, este exercício da posse se dará de maneira diferente em cada um dos grupos dos direitos reais sobre coisas alheias (fruição ou garantia).

Enquanto que nos institutos de direito real de fruição (enfiteuse, superfície, servidões, usufruto, uso e habitação) o possuidor mantém consigo a chamada posse fruendi, ou seja, aquela posse cujo titular pode usar da coisa em seu próprio proveito, tendo como obrigação apenas e tão somente evitar o seu perecimento, já nos direitos reais de garantia (penhor, propriedade fiduciária, anticrese e hipoteca), esta posse será meramente garantidora, ou seja: o possuidor não pode usar a coisa em seu proveito (salvo em raras exceções permitidas por lei), mas tão somente tê-la consigo para que, caso não receba seu crédito, use-a para apurá-lo (o crédito) em hasta pública (é o que ocorre, por exemplo, nos casos de penhor e propriedade fiduciária). Sobre tais diferenças no exercício da posse, voltaremos a falar mais adiante, quando criticaremos a natureza jurídica da anticrese, classificada em todos os tempos como direito real de garantia.

\subsubsection{Dos Efeitos dos Direitos Reais de Garantia}

Os direitos reais de garantia são dotados de três (03) efeitos específicos, a saber: efeito da especificidade, efeito da indivisibilidade (em relação ao bem dado em garantia e em relação ao pagamento do crédito) e o efeito da excussão.

O Efeito da Especificidade encontra seu fundamento nos artigos 1.362 e 1.424 do Código Civil que determina o seguinte:

Art. 1362. O contrato, que serve de título à propriedade fiduciária, conterá:

I - o total da dívida, ou sua estimativa;

II - o prazo, ou a época do pagamento;

III - a taxa de juros, se houver;

IV - a descrição da coisa objeto da transferência, com os elementos indispensáveis à sua identificação.

(...)

Art. 1424. Os contratos de penhor, anticrese ou hipoteca declararão, sob pena de não terem eficácia:

Nota: Ver dispositivo equivalente do antigo Código Civil - Lei no 3.071, de 1916 texto alterado.

I - o valor do crédito, sua estimação, ou valor máximo;

II - o prazo fixado para pagamento;

III - a taxa dos juros, se houver;

IV - o bem dado em garantia com as suas especificações. 
Em suma: para que as garantias reais sejam válidas perante terceiros, além do registro no cartório competente (ato indispensável para o caráter real), dos respectivos contratos devem constar expressamente os requisitos dos artigos acima expostos: identificação precisa do bem dado em garantia, o valor do crédito, o prazo fixado para pagamento e a taxa de juros se houver. A inobservância de um destes requisitos leva à nulidade da garantia perante terceiros.

Já o Efeito da Indivisibilidade, que encontra espeque no artigo 1.421 do Código Civil determina que "o pagamento de uma ou mais prestações da dívida não importa exoneração correspondente da garantia, ainda que esta compreenda vários bens, salvo disposição expressa no título ou na quitação”.

Em suma, o Efeito da Indivisibilidade, em sede de direitos reais de garantia, determina que o bem dado em garantia ficará INTEGRALMENTE COMPROMETIDO ATÉ O PAGAMENTO TOTAL DO CRÉDITO. Ou seja: não importa que o crédito seja de valor muito inferior ao bem garantidor, ou se o crédito já foi quase que completamente pago. Tanto em um caso como no outro, o bem continuará garantindo o cumprimento da obrigação de maneira INTEGRAL e INDIVISIVELMENTE.

O efeito da indivisibilidade pode ser encarado sob dois prismas: da indivisibilidade quanto ao objeto garantidor e da indivisibilidade quanto ao valor garantido.

Pelo primeiro prisma (indivisibilidade quanto ao objeto garantidor) podemos imaginar, por exemplo, que alguém, para garantir o pagamento de uma dívida de vinte mil reais, preste em garantia um imóvel de cem mil reais. Este imóvel, embora corresponda a cinco vezes o valor da dívida contraída, responderá pela mesma em toda a sua integralidade, não havendo a possibilidade de comprometer apenas parte do bem.

Já pelo segundo prisma (indivisibilidade quanto ao valor garantido), podemos imaginar, por exemplo, alguém que tenha contraído uma dívida de vinte mil reais, e que tenha convencionado o seu pagamento em vinte parcelas. Este devedor, já tendo pago dezenove destas, continuará tendo o seu bem (que fora dado em garantia) COMPLETAMENTE e INDIVISIVELMENTE vinculado ao cumprimento da obrigação até o pagamento da última parcela. Ou seja: "o pagamento de uma ou mais prestações da dívida, não importa exoneração correspondente da garantia” (art. 1.421 do Código Civil).

Já o Efeito da Excussão se constitui corolário ao Efeito da Indivisibilidade. Com isto, queremos dizer que uma vez não pago o débito, resta ao credor o direito de excutir o bem dado em garantia. Excutir significa, precisamente, levar o bem dado em garantia a hasta pública para que, do produto apurado em sua venda, o credor possa retirar o que lhe é devido, 
devolvendo o que sobejar do preço ao devedor. Assim dispõe o artigo 1.422 do Código Civil brasileiro:

Art. 1422. O credor hipotecário e o pignoratício têm o direito de excutir a coisa hipotecada ou empenhada, e preferir, no pagamento, a outros credores, observada, quanto à hipoteca, a prioridade no registro.

Como entre nós já não é mais possível o pacto comisstório (antiga disposição das Ordenações do Reino que autorizava ao credor de direito real se assenhorear do bem dado em garantia se o seu crédito não fosse pago), justamente por tal prática implicar em forma de locuplentamento por parte do credor real, este, por nosso ordenamento, deve receber o seu crédito pela concorrência pública na venda do bem oferecido em garantia real, o que se faz mediante hasta pública. Desta forma, é possível que, procedida a venda da garantia real, paga a importância devida ao credor, seja devolvido ao devedor o que porventura tenha sobejado da venda da garantia real.

Em virtude do efeito da indivisibilidade acima estudado, vimos que não é possível que apenas uma parte da garantia real responda pelo débito. Daí a justificativa de sua alienação para o cumprimento de seu papel garantidor da obrigação.

\section{DO EQUÍVOCO EM SE CLASSIFICAR A ANTICRESE COMO GARANTIA REAL}

Tendo em vista todas as considerações até aqui propostas, analisadas as características e efeitos específicos das garantias reais, tentaremos demonstrar neste item as razões que nos levam a discordar do caráter de garantia real emprestado ao instituto da anticrese pelo nosso ordenamento civil. Peca, portanto, o presente Código em dois momentos: a) em não retirar de nosso ordenamento civil instrumento já completamente em desuso no trato diário; b) em se fazendo a opção pela sua mantença, não procedeu o legislador com a devida reclassificação da anticrese, retirando-lhe o caráter de garantia real, como sugeriremos a seguir.

\subsection{Da não recepção pela anticrese dos Efeitos da Indivisibilidade e da Excussão}

Começaremos pela demonstração da não recepção pela anticrese, de dois, dos três efeitos típicos das garantias reais acima estudados: os efeitos da indivisibilidade e da excussão.

Primeiramente, não podemos dizer que a anticrese seja marcada pelo efeito da indivisibilidade. Ora. A anticrese constitui, exatamente, no direito do credor anticrético retirar do imóvel dado em anticrese a importância que lhe é devida, por meio de sua administração 
direta, reduzindo o seu crédito à medida que vão sendo colhidos os frutos do imóvel anticrético.

Assim, à medida que o credor anticrético se utiliza do bem dado em anticrese, o seu crédito sofrerá abatimento proporcional. E muito embora o bem, na sua integralidade, continue servindo de garantia anticrética (ou seja: embora exista o efeito da indivisibilidade em razão do bem prestado em garantia), não estaria presente a indivisibilidade sob o prisma do valor garantido, já que a exploração sobre o imóvel deverá diminuir de intensidade à medida que a dívida for sendo paga.

Imaginemos, por exemplo, um garimpo de ouro que tenha sido cedido em anticrese, rendendo ao credor anticrético o montante de $\mathrm{R} \$ 10.000,00$ diários, respondendo por uma garantia anticrética no valor de $\mathrm{R} \$ 100.000,00$. Obviamente, à medida que o devedor anticrético explore aquele garimpo, cada vez menos ouro será preciso retirar daquele imóvel para a liquidação do crédito.

Certo dia, digamos que imaginemos, por exemplo, um garimpo de ouro que tenha sido cedido em anticrese, rendendo ao credor anticrético obrigação, credor anticrético já houvera retirado daquele garimpo o equivalente a $\mathrm{R} \$ 98.000,00$ de seu crédito, por exemplo, extraiu daquele imóvel o equivalente a $\mathrm{R} \$ 15.000,00$ a mais.

Portanto, os $\mathrm{R} \$ 13.000,00$ que sobejaram não foram apropriados pelo credor, já que este fazia jus a apenas $\mathrm{R} \$ 2.000,00$ para a complementação de seu crédito.

Não há como negar que a exploração empregada no garimpo até aquela data importou na exoneração correspondente da garantia.

Desta forma, não se aplica à anticrese o artigo 1.421 do Código Civil (dispositivo pertencente às disposições gerais dos direitos reais de garantia).

Muito menos ainda, poder-se-ia falar da existência do efeito da excussão em sede de anticrese.

Ora. Se a garantia anticrética consiste (única e tão somente) no direito do credor anticrético em perceber os frutos que o imóvel dado em anticrese venha a produzir sob a sua administração, para que daí, o próprio credor resgate o seu crédito, definitivamente, o imóvel anticrético não está sujeito a qualquer tipo de gravame, pois, repita-se, não é ele que está a garantir o crédito, mas sim os frutos que este venha a produzir sob a administração do credor. Nas palavras de Maria Helena Diniz:

“c.2. Direitos e deveres do credor anticrético

$\mathrm{O}$ anticresista tem direitos de: 
1) Reter o imóvel do devedor pelo prazo de 15 anos, se outro menor não for avençado pelas partes (C.C. art. 1.423) ou até que seu crédito seja pago (C.C, art. $1.507, \S 2^{\circ}$, in fine). Não lhe assiste o direito de excutir o imóvel”. (grifos nossos). (DINIZ, Maria Helena. Curso de Direito Civil Brasileiro. V. 4. p. 460. 17.ed. atual. de acordo com o novo Código Civil. São Paulo: Saraiva, 2002.)

Portanto, diante do inadimplemento da obrigação, em hipótese alguma poderá ser o imóvel excutido, já que não é ele o objeto da garantia. E reforçando nosso entendimento, o próprio Código Civil assim o diz expressamente, ao retirar do artigo 1.422 (supra citado) a figura do credor anticrético como sujeito que possa pedir a excussão de sua garantia real.

\subsection{Da cumulação da anticrese e da hipoteca sobre o mesmo imóvel. Impossibilidade de cumulação de garantias reais sobre o mesmo bem.}

Outra característica da anticrese que leva-nos a reforçar o entendimento de que tal instituto não pode ser considerado como sendo de garantia real é o fato de ser possível o imóvel cedido em anticrese poder ser cedido também em hipoteca e vice-versa.

Definitivamente, não é possível que sobre o mesmo bem recaia mais que uma garantia real. Caso contrário, estaríamos desguarnecendo o credor real. Ora. O que confere maior garantia quanto ao recebimento do crédito real é exatamente o fato de que aquele bem representa garantia exclusiva de apenas um credor. Este fato assegura o recebimento do crédito por parte deste credor, na medida em que não possibilita o concurso de credores sobre aquele bem específico. Ou seja: a garantia real representa exclusividade para o seu credor.

Tal fato apenas não ocorre na hipoteca, pois neste caso, como os bens passíveis de tal garantia se tratam de bens de difícil alienação e de grandes valores, é possível que possam ser utilizados em garantia mais que uma vez (até o limite do valor do bem).

\subsubsection{Finalidade da garantia real: meio reparatório pelo não pagamento espontâneo da obrigação}

Outro ponto que nos leva a discordar da classificação da anticrese como modalidade de garantia real, encontra-se na própria finalidade da garantia real. A garantia real (como qualquer outra) somente é utilizada caso haja o inadimplemento da obrigação pelo devedor. Uma vez satisfeita a obrigação, o bem dado em garantia fica liberado do ônus, voltando a ser de propriedade exclusiva e plena do antigo devedor.

Tal fato não ocorre na anticrese. Isto porque, assim que o bem é disponibilizado por meio desta garantia, imediatamente o credor já passa a explorá-lo; a retirar-lhe proveito. A 
anticrese, por sua natureza, implica em permitir que o seu credor se utilize do bem, de maneira ativa, para que, deste uso, ele (o credor) tenha o seu crédito pago.

Dizemos melhor: a figura da garantia somente é exercida caso não seja pago o débito. Já na anticrese, o credor anticrético, tão logo assim se constitua, já passa a receber o seu crédito imediatamente, por sua própria administração, não ficando, por isto mesmo, condicionado a nenhum fato anterior (inadimplemento da obrigação). Afinal, o inadimplemento, em sede de anticrese, significaria, exatamente, o seu não exercício.

Note, então, que o que ocorre na anticrese se assemelha mais a uma modalidade especial de pagamento, ou de contrato creditício, do que a uma garantia. O professor Caio Mário da Silva Pereira, em sua clássica obra Instituições de Direito Civil, já opinava que o futuro deste instituto seria de tender, senão ao desaparecimento, ao menos de mudança de seu caráter:

"É provável que no futuro venha a (anticrese) perder a categoria de direito real, subsistindo como contrato de natureza meramente creditícia ou cláusula adjecta a contrato hipotecário." (PEREIRA, Caio Mário da Silva. Instituições de Direito Civil. Rio de Janeiro: Forense, 2004. p. 416).

A não utilização do instituto em nosso cotidiano não justifica que desconsideremos a sua existência, nem que deixemos de raciocinar em seus efeitos no contexto global civil, o que exige o nosso constante debate. Afinal, o progresso de toda e qualquer ciência está inexoravelmente ligado ao constante debate e observação das coisas que nos são postas, a princípio, como verdades únicas, sem espaços para mudanças.

\section{REFERÊNCIAS}

GAMA Afonso Dionísio. Dos Direitos Reaes de garantia: penhor, anticrese e hypotheca. 2. ed. São Paulo. Acadêmica, 1930

GOMES, Orlando; THEODORO JÚNIOR, Humberto. Direitos reais. 11. ed. Rio de Janeiro: Forense, 1995

MONTEIRO, Washington de Barros; PINTO, Ana Cristina de Barros Monteiro França. Curso de direito civil. 38. ed. rev. e atual. por Ana Cristina de Barros São Paulo: Saraiva, 2001. 6v.

PEREIRA, Caio Mário da Silva. Instituições de direito civil. 14. ed. Rio de Janeiro: Forense, 2000

RIZZARDO, Arnaldo. Direito das coisas. Rio de Janeiro: Aide, 1991. 3v. I

RODRIGUES, Sílvio. Direito civil. 32. ed. atual. São Paulo: Saraiva, 2002.

Revista da Faculdade Mineira de Direito, v.12, n. 24, jul./dez. 2009 - ISSN 1808-9429. 